\title{
Treating Idiopathic Male Infertility with a Combination of Tamoxifen Citrate and a Natural Compost with Antioxidant and Androgen-Mimetic Action
}

\author{
lacono F, Prezioso D , Ruffo A*, Di Lauro G, Illiano E, Romeo G and Romis L \\ Department of Urology, University "Federico II" of Naples, Italy
}

\section{Abstract}

Background: We investigated the efficacy of a combination therapy with tamoxifen citrate and a natural composite containing Tribulus terrestris, alga Ecklonia bicyclis and polymers of d-glucosamine and n-acetyl d-glucosamine in treating male idiopathic infertility.

Methods: In this prospective, randomized double blind, placebo-controlled study, we enrolled ninety infertile men at our department of urology at University Federico II of Naples. Mean age was $29.2 \pm 7.8$ [ \pm SD]. Inclusion criteria consisted of the repeated exhibition of oligoasthenozoospermia (OA) without detectable cause (unexplained $O A$ ). Patients were randomly assigned to three treatment groups: Group A $(n=30)$ receiving tamoxifene citrate $(20 \mathrm{mg} /$ day $)$ and a natural composite with an antioxidant and androgen-mimetic action (150 mg of alga Ecklonia Bicyclis, $396 \mathrm{mg}$ of Tribulus terrestris and $144 \mathrm{mg}$ of polymers of d-glucosamine and $n$-acetyl d-glucosamine); Group $B(n=30)$ receiving tamoxifene citrate $(20 \mathrm{mg} /$ day) and Group $\mathrm{C}$ receiving placebo $(\mathrm{n}=30)$. We evaluated the number of spontaneous pregnancies, sperm volume, concentration, sperm total motility, sperm forward progressive motility, normal sperm morphology

Results: After 6 months of therapy the number of spontaneous pregnancies was markedly higher in the Group A (13 pregnancies, 33.3\%) then the other two groups: Group B (6 pregnancies, 20\%) and Group C (4 pregnancies, $13.3 \%$ ). Sperm concentration improved in the Group A from a mean $8.49 \times 10^{6} \mathrm{cell} / \mathrm{sl} \pm 5.57$ at baseline to $22.1 \times$ $10^{6} \mathrm{cells} / \mathrm{ml} \pm 1,63(\mathrm{p} \leq 0.001)$. In the Group B there was an improvement from a mean $7.98 \times 10^{6}$ at baseline to 14.43 $\times 10^{6} \mathrm{cells} / \mathrm{ml} \pm 3,43(p=0.002)$. Group $C$ did not see a statistically significant improvement of sperm number, from a concentration of $9.65 \times 10^{6}$ cells $/ \mathrm{ml} \pm 6.54$ to $10.53 \times 10^{6} \mathrm{cells} / \mathrm{ml} \pm 8.5(p=0.0025)$. In Group A, sperm total motility improved from $31 \% \pm 11 \%$ at baseline to $40 \% \pm 14 \%$ ( $p=0.007$ ) whilst the forward progressive motility slightly improved from $5 \% \pm 3 \%$ to $9 \% \pm 4 \%(p=0.0034)$. In the group B and $C$, there were not reported statistically significant changes of motility.

Conclusions: The combination therapy with tamoxifen citrate and the natural compound with an andorgen-mimetic and antioxidant action leads to a higher incidence of pregnancy rates and gives a statistically significant improvement of semen parameters comparing with the single use of tamoxifen citrate and with the control group.

Keywords: Male infertility; Antioxidant; Oligospermia; Oligoasthenozoospermia (OA); Tamoxifen citrate

\section{Background}

Infertility is one of the most important issues among married couples and it represents a major clinical problem affecting people not just medically but psychologically too.

It has been demonstrated that $15 \%$ of all the couples in the US are infertile and male factor is responsible for the $25 \%$ of the cases [1].

Couples that have not achieved a pregnancy in the last 12-24 months are considered as barren.

The cause of male infertility with abnormal semen parameters remains unknown in $25 \%$ of men [2]. In many Western countries, women postpone their first pregnancy until they have finished their education and have started a career, so also female age is the important variable influencing outcome in assisted reproduction. In fact compared to a woman at 25 years old, the fertility potential is reduced to $50 \%$ at age 35 , to $25 \%$ by 38 years and $<5 \%$ at over 40 years [ 3 ].

Men with idiopathic infertility are prone to receive a number of empirical therapies.

Otherwise while $25 \%$ of men with sperm density lower than 12.5 million per $\mathrm{ml}$ could father a child through spontaneous conception,
$10 \%$ with a normal female partner cannot contribute to pregnancy even with a number of more than 25 million per $\mathrm{ml}$ [3].

These findings suggest that there could be other parameters that affect pregnancy and study outcomes based only on improvement in semen parameters are not enough. A more effective outcome parameter would probably be the pregnancy rate since that is the ultimate end point of therapy. Commonly used medications include hormonal medications as follicle stimulating hormone (FSH), androgens (mesterolone, testosterone undecanoate/enanthate) $[3,4]$ and antiestrogen (tamoxifen/clomiphen citrate); antioxidant like glutathione, lycopene, vitamin E; Sperm vitalizer as L-carnitine, coQ10.

*Corresponding author: Ruffo A, Department of Urology, University "Federico II" of Naples Via S. Pansini, 5 - 80131 Naples , Italy, Tel: +39 3339323372, +39 0817462607; E-mail: antonio.ruffo7@gmail.com

Received January 28, 2013; Accepted March 13, 2013; Published March 31 2013

Citation: lacono F, Prezioso D , Ruffo A, Di Lauro G, Illiano E, et al. (2013) Treating Idiopathic Male Infertility with a Combination of Tamoxifen Citrate and a Natura Compost with Antioxidant and Androgen-Mimetic Action. J Steroids Hormon Sci S5: 002. doi:10.4172/2157-7536.S5-002

Copyright: ( 2013 lacono F, et al. This is an open-access article distributed unde the terms of the Creative Commons Attribution License, which permits unrestricted use, distribution, and reproduction in any medium, provided the original author and source are credited. 
Citation: lacono F, Prezioso D, Ruffo A, Di Lauro G, Illiano E, et al. (2013) Treating Idiopathic Male Infertility with a Combination of Tamoxifen Citrate and a Natural Compost with Antioxidant and Androgen-Mimetic Action. J Steroids Hormon Sci S5: 002. doi:10.4172/2157-7536.S5-002

Page 2 of 6

Of the many causes of male infertility, oxidative stress (OS) has been shown to affect the fertility status and for this reason it has been widely studied in the past few years.

Spermatozoa, like all other aerobic cells are particularly susceptible to oxidative stress induced damage because of the large polyunsaturated fat content in their membranes. Men with high ROS may have a lower fertility potential compared to those with low ROS [5].

High levels of reactive oxygen species in semen have been correlated with reduced sperm motility and damage to sperm nuclear DNA [5].

For example, IL-1 $\alpha$, IL-1 $\beta$ and tumor necrosis factor $\alpha$ TNF- $\alpha$ ), stimulate sperm peroxidation by increasing ROS generation [6]; IL-6 has been shown to play a pivotal role in the induction of capacitation and the acrosomal reaction in sperm [7]. However, high levels of cytokines in the semen have been correlated with sperm injury, most notably cell membrane lipid peroxidation in the presence of elevated IL-6 $[6,8]$. Further, increased levels of IL- 6 have also been noted in the seminal fluid of infertile men [9].

Also, IL-1, IL-6, IL-8 and TNF have all been shown to induce increased ROS production, leading to increased sperm cell membrane lipid peroxidation $[6,8,10]$.

Interferon gamma (IFN- $\gamma$ ) and TNFa have been shown to decrease the motility of spermatozoa.

This condition is common in cases of genitourinary tract infections and inflammation, in which oxidative mechanism produce the oxidative stress [11].

Antioxidants in seminal plasma are the most important form of protection available to spermatozoa against ROS $[6,12]$.

That is why it is commonly used to prescribe antioxidant oral therapy for the idiopathic male oligoastenospermia to decrease oxidative stress and improve fertility.

Antiestrogens have been one of the oldest and most commonly prescribed forms of therapy for idiopathic male infertility. These drugs inhibit the negative feedback effect of estrogen on the hypothalamus and pituitary, increasing endogenous gonadotropin secretion.

Antiestrogen therapy was reported to yield pregnancy rates ranging from $20 \%-40 \%$ following 6-9 months of therapy [13] from the hypothalamus and FSH and LH secretion directly from the pituitary, increasing their levels, thereby stimulating spermatogenesis [14].

Pregnancy rates following varicocelectomy were approximately $40 \%[15]$.

\section{Methods}

This is a prospective, randomized double blind, placebo-controlled study. We enrolled ninty infertile men attending our department of urology at University Federico II of Napsssles. Mean age of male partner was $29.2 \pm 7.8[ \pm \mathrm{SD}]$ while female partner mean age was $27.4 \pm 6.8[ \pm$ $\mathrm{SD}]$. We included a minimum of 1 year of regular unprotected sexual activity without achieving pregnancy. Inclusion criteria consisted of the repeated exhibition of oligoasthenozoospermia without detectable cause (unexplained OA). We evaluated the number of spontaneous pregnancy, sperm volume and concentration, sperm total motility, forward progressive motility and normal morphology.

Exclusion criteria included cases with known etiology or leukocytospermia, and alterated testicular volume, varicocele (as detected by clinical examination and ultrasonography) or an abnormal FSH level. Couples with combined male and female factors were excluded. Patients signed a informed consent explaining the nature of the study, the possibility of treatment failure, and possible side effects. They underwent a clinical evaluation including history taking, general examination, and genital examination for possible causes of infertility. Investigations for the male partner included semen analysis according to World Health Organization criteria [16]. Only couples with no female factor infertility were included in the study.

Patients were blindly randomized into three groups: Group A (time of infertility $2.4 \pm 1.2$ years $[ \pm \mathrm{SD}]$ ) receiving a combination of an antiestrogen [tamoxifen citrate $20 \mathrm{mg} /$ day] and a natural composite with an antioxidant and androgen-mimetic action [150 $\mathrm{mg}$ of alga Ecklonia Bicyclis, $396 \mathrm{mg}$ of Tribulus terrestris and $144 \mathrm{mg}$ of polymers of d-glucosamine and $n$-acetyl d-glucosamine (Tradamix $\left.{ }^{\circledR}\right) ; n=30$ ]; Group B (time of infertility $2.2 \pm 1.1$ years $[ \pm S D]$ ) receiving tamoxifen citrate $(n=30)$ and Group $C$ (time of infertility $1.9 \pm 1.0$ years $[ \pm$ SD] receiving placebo $(n=30)$. Treatment was continued for 6 months. All statistical measurements were performed using ANOVA tests. We wanted to have a level of significance with $\mathrm{p}<0.05$.

\section{Results}

After 6 months of therapy the cumulative number of pregnancy was markedly higher in the Group A (13 pregnancies, 33.3\%) then the other two groups: Group B (6 pregnancies, 20\%) and Group C (4 pregnancies, $13.3 \%)$. This difference is statistically significant $(\mathrm{p}=0.023)$ (Table 1).

In the tables 1 and 2 , are reported the changing in semen parameters before and after treatment in the three groups.

Sperm concentration significantly improved in the Group A from a mean $8.49 \times 10^{6}$ cells $/ \mathrm{ml} \pm 5,57$ at baseline to $22.1 \times 10^{6}$ cells $/ \mathrm{ml} \pm 1,63$ ( $\mathrm{p} \leq 0.001$ ) comparing with the tamoxifen recipients (Group B) where the was an improvement from a mean $7.98 \times 10^{6}$ at baseline to $14.43 \times$ $10^{6} \mathrm{cells} / \mathrm{ml} \pm 3.43(\mathrm{p}=0.002)$. Group $\mathrm{C}$ had an improvement of sperm number, from a concentration of $9.65 \times 10^{6} \mathrm{cells} / \mathrm{ml} \pm 6.54$ to 10.53 $\times 10^{6}$ cells $/ \mathrm{ml} \pm 8.5(\mathrm{p}=0.0025)($ Table $2 \mathrm{~A})$.

\begin{tabular}{|l|c|c|c|c|}
\hline Group & Cases & $\begin{array}{c}\text { Pregnancies } \\
(\mathbf{1 - 3} \text { mo) }\end{array}$ & $\begin{array}{c}\text { Pregnancies } \\
\text { (3-6 mo) }\end{array}$ & $\begin{array}{c}\text { Total } \\
\text { pregnancies }\end{array}$ \\
\hline Tamoxifen+Tradamix & 30 & 6 & 7 & $\begin{array}{c}13(33.3 \%, \\
p=0.025)\end{array}$ \\
\hline Tamoxifen & 30 & 3 & 3 & $\begin{array}{c}6(20 \%, \\
p=0.032)\end{array}$ \\
\hline Placebo & 30 & 2 & 2 & $\begin{array}{c}4(13.3 \%, \\
p=0.038)\end{array}$ \\
\hline
\end{tabular}

Table 1: Pregnancy rates in the 3 Groups.

\begin{tabular}{|l|c|c|c|c|c|}
\hline \multicolumn{7}{|c|}{ Semen parameters before treatment } \\
\hline Group & Volume (ml) & Count $\left(\times \mathbf{1 0}^{\mathbf{6}}\right)$ & TM (\%) & FPM (\%) & ABF (\%) \\
\hline Tamoxifen+Tradamix & 2.4 & 8.49 & 31 & 5 & 37 \\
\hline Tamoxifen & 2.2 & 7.98 & 30 & 8 & 39 \\
\hline Placebo & 2.5 & 9.65 & 29 & 6 & 37 \\
\hline
\end{tabular}

Table 2A: Semen parameters before treatment in the 3 Groups.

\begin{tabular}{|l|c|c|c|c|c|}
\hline \multicolumn{6}{|c|}{ Semen parameters after treatment } \\
\hline Group & Volume (ml) & Count (× 10 & TM (\%) & FPM (\%) & ABF (\%) \\
\hline Tamoxifen+Tradamix & 3.2 & 22.1 & 40 & 7 & 35 \\
\hline Tamoxifen & 2.7 & 21.6 & 35 & 5 & 38 \\
\hline Placebo & 2.9 & 10.53 & 30 & 4 & 48 \\
\hline
\end{tabular}

Table 2B: Semen parameters after treatment in the 3 Groups. 
Citation: lacono F, Prezioso D, Ruffo A, Di Lauro G, Illiano E, et al. (2013) Treating Idiopathic Male Infertility with a Combination of Tamoxifen Citrate and a Natural Compost with Antioxidant and Androgen-Mimetic Action. J Steroids Hormon Sci S5: 002. doi:10.4172/2157-7536.S5-002

In Group A sperm total motility improved from $31 \% \pm 11 \%$ at baseline to $40 \% \pm 14 \%(\mathrm{p}=0.007)$ whilst the forward progressive motility slightly improved from $5 \% \pm 3 \%$ to $9 \% \pm 4 \%$ ( $p=0.0034)$. For the other two groups there were not reported statistically significant changes of motility (Table 2B).

Seminal volume did not change after the treatment in the Group A $(2.47 \pm 1.4$ at baseline, $2.9 \pm 1.6$ at 6 months) and no difference from Group B and placebo recipients (Group C) were observed.

No remarkable difference in sperm form was reported.

\section{Discussion}

In this study, we evaluated the effectiveness of the combination of tamoxifen citrate and this natural compost in treating idiopathic male infertility. Combination therapy for male infertility has been evaluated by other investigators. Comhaire et al. [17] studied 30 men with infertility and female partners with no demonstrable cause of infertility who received conventional treatment according to the guidelines of the World Health Organization [16], and either a strong antioxidant, astaxanthin ( $16 \mathrm{mg} /$ day), or a placebo for 3 months. The results revealed total pregnancy rates of $10.5 \%$ among the placebo cases, compared with 54.5 in the active treatment $\operatorname{arm}(\mathrm{p}=0.028)$.

Our results (Table 1) are similar with the findings of Adamopolous and Comhaire, and suggest that combination therapies for male infertility should be further evaluated $[18,19]$.

A recent short review assessing evidence-based treatments for male infertility show many methodological difficulties with these works [20] given by the short duration of most of these studies. Although married couples are allowed 1 year of unprotected intercourse to conceive before a diagnosis of infertility is made, most studies allow only an average of 3 months of observation, even if seminal parameters improve. Results of medical treatment in terms of cumulative pregnancy rates may differ if the observation period is long enough. This has been clearly suggested by the improved pregnancy rate after 6 months shown in our work as well as by Adamopolous et al. [18] and Ghanem et al. [20]. This study suggests that combination of an antiestrogen with a substance with an antioxidant and androgen-mimetic action is a valid therapy for men with oligoasthenozoospermia.

This composite $\left(\right.$ Tradamix $^{\mathbb{R}}$ ) contains these three compounds: alga Ecklonia bicyclis, Tribulus terrestris and polymers of d-glucosamine and n-acetyl-d-glucosamine.

Alga bicyclis is a macro algae widely distributed along the Pacific coast of central Japan and Korea where, when conditions are suitable, forming extensive underwater meadows (kelp forests), often mixed. The biological properties attributed to these species are instead traced to the presence of particular secondary metabolites also known as the phlorotannins and made the union of various units of the same monomer, the 1,3,5-triidrossi phenol or phloroglucinol. So far a dozen such compounds has been identified, the most important of which are shown in the figures [21-24]. Right now, more than 20,000 new compounds have been isolated from marine organisms; numbers of these naturally occurring derivatives are developed as potential candidates for pharmaceutical applications. Phlorotannins are secondary metabolites distributed in a variety of plants. They are phloroglucin derivatives with a variety of biological functions in vitro and in vivo, such as a strong radical scavenging and antioxidant action $[25,26]$.

Ecklonia cava radical scavenger activity $10-100$ powerful than any other polifenol terrestris plants, including green tea catechins, which have only 3-4 fenolic and rings that are commonly considered among the most effective antioxidant molecules. Common polyphenols are soluble in water also and have a relatively short half-life introduced into the body. All phlorotannins had antioxidant properties in vitro, especially, bieckol, dieckol and phlorofucofuroeckol [26] (Figures 1-3).

Inflammatory cells might generate and release a number of inflammatory mediators: for example, proinflammatory cytokines and inflammatory cytokines, such as interleukins [27-30], TNF- $\alpha$ [27-30], p53 [31], cytochrome P-450 [27-32] and NADPH-cytochrome P-450 [27-31] causing abnormal metabolism of the hypoxanthine/xanthine oxidase system and the xanthine/xanthine oxidase system, producing many abnormal metabolites [27-33].

These inflammatory cells and reactions might also activate and release a large amount of COX-2 [27-29] transcription NF-k B [27-29] iNOS, and an amount of inflammatory oxidants and other chemokines $[27,34,35]$ and without question, they might induce, generate and release a large number of $\mathrm{O}_{2}^{-}, \cdot \mathrm{OH}, \mathrm{NO}$ and other free radicals, as well as $\mathrm{O}_{2}, \mathrm{H}_{2} \mathrm{O}_{2}$, and other $\mathrm{ROS}[27,28,31,33,34]$. Excessive free radicals and ROS, as strong oxidants, might affects replication and transcription<smiles>C=C(C)Oc1c(O)cc(O)c2c1Oc1c(cc(O)c(-c3c(O)cc4c(c3O)Oc3c(O)c(O)cc(C)c3O4)c1O)O2</smiles>

Figure 1: Bieckol.<smiles>CCc1cc(CC)cc(Oc2c(O)cc(O)c3c2Oc2cc(Oc4c(O)cc(Oc5c(O)cc(O)c6c5Oc5c(O)cc(O)cc5O6)cc4O)cc(O)c2O3)c1</smiles>

Figure 2: Dieckol. 
<smiles></smiles>

Figure 3: Phlorofucofuroeckol.

of mtDNA and results in a decline in mitochondrial function which in turn leads to enhanced ROS production and further damage to mtDNA [36].

In the Ecklonia cava there are molecules that are able to reduce the response inflammatory, partially neutralizing the inflammatory damage caused by ROS and in part by slowing the gaming lipoxygenase and inhibiting the formation of prostaglandin E2, a powerful inflammatory mediator. Jung et al. revealed that dieckol inhibits LPS-induced NO and $\mathrm{PGE}_{2}$ [37] production in a concentration-dependent manner and inhibits inducible iNOS and COX-2 in BV2 microglia without causing $[38,39]$. Alga ecklonia treatment significantly reduced NF-kB translocation and DNA-binding in LPS-stimulated BV2 microglia [39] and p38 mitogen-activated protein kinases (MAPKs) activation [37].

Phlorotannins suppresses the induction of cytokines by LPS, as well as iNOS and COX-2 expression, by blocking NF-kappaB and MAPK activationas well as reactive oxygen species (ROS) production [39]. These findings provide mechanistic insights into the anti-inflammatory and neuroprotective actions of EC in BV2 microglia [40]. It also significantly reduced the generation of proinflammatory cytokines, such as interleukin (IL)- $1 \beta$ and tumor necrosis factor (TNF)- $\alpha$.

Kim et al. revealed extracts reduced the concentrations of IL- 4 and IL- 5 by $66 \%$ and $84 \%$, respectively, and resulted in a $73 \%$ reduction in the secretion of TNF- $\alpha$ [35].

The second compound contained in the composite used in this therapy is Tribulus terrestris. This plant native of India, but now present in most of North America has a weed Active ingredients: protodioscin. The plant contains also flavonoids, alkaloids and amides, although its properties seem to be completely attribuited to protodioscin (Figure 4).

The parts used are the seeds and fruits, and, more generally, the aerial parts of the plant. The protodioscin is a steroidal saponin, which is about $45 \%$ of the extract obtained from aerial parts of Tribulus terrestris (Figure 4). The substance is able to increase the endogenous production of testosterone, dihydrotestosterone, a hormone luteinizing hormone (LH), dehydroepiandrosterone (DHEA) and dehydroepiandrosterone sulfate (DHEA-S) [40]. Because of these effects in experimental animals there is an increase in spermatogenesis and the frequency of matches [41]. In the rabbit in particular has been shown that the compound stimulates the release of nitric oxide (NO) by vascular endothelium of the corpora cavernosa thereby having a pro-erectile effect [41]. The mechanism behind this effect appears to involve the pathway of steroid hormones [41]. Although humans protodioscin is used for the treatment of erectile dysfunction $[42,43]$.

A study conducted on 150 italian patients affected by erectile dysfunction treated with the same composite containing Tribulus terrestris, alga Ecklonia bicyclis and polymers of d-glucosamine and n-acetyl-d-glucosamne showed and improvement of $28 \%$ of the testosterone levels from a baseline mean value of $5.3 \pm 1.1 \mathrm{ng} / \mathrm{ml}$ to 6.8 $\pm 1.6(\mathrm{p}<0.01)$ post treatment [44].

Polymers of d-glucosamine and n-acetyl-d-glucosamine acts on as a nitric oxide synthetase (NOS) stimulator [44] (Figure 5).

Nitric oxide (NO) is a free radical generated from the oxidation of $\mathrm{L}$-arginine to $\mathrm{L}$-citrulline by reduced nicotinamide adenine dinucleotide phosphate (NADPH)-dependent nitric oxide synthase (NOS). Nitric oxide is diffusible, multifunctional, and acts as a transcellular messenger, being implicated in numerous physiologic and pathologic conditions [45].

Nitric oxide, at physiologic concentrations, is relatively nonreactive, but most of its actions are mediated by activation of cyclic guanosine monophosphate production [46]. It is reported that NO modulates sexual and reproductive functions in mammalian species $[47,48]$. The presence of NO in seminal plasma has been confirmed [49]. The source of NO in seminal plasma may be either male reproductive organs or macrophages [50,51]. The production of NO in human and animal sperm has also been reported $[50,51]$

Nitric oxide is reported to be a novel mediator of sperm function [52]. It has both positive and negative effects. The positive modulation reflects the role of $\mathrm{NO}$ in physiologic processes like sperm capacitation [52] and acrosome reaction [53].

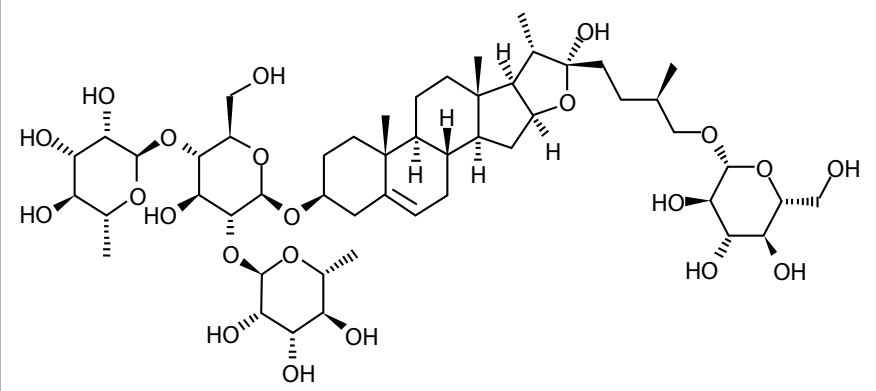

Figure 4: Protodioscin contained in Tribulus terrestris.

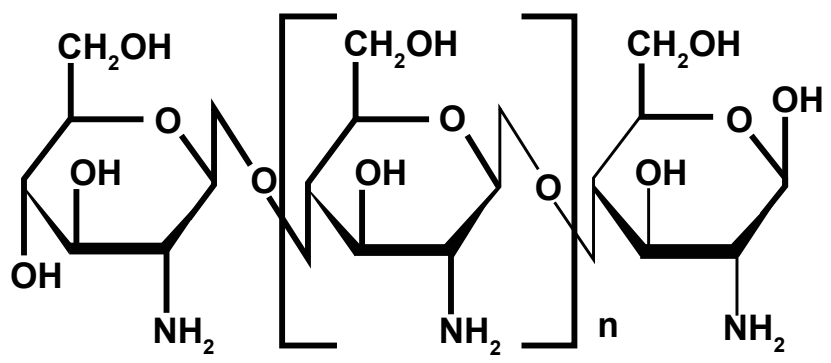

Figure 5: Polymers of d-glucosamine and n-acetyl-d-glucosamine. 
Citation: lacono F, Prezioso D, Ruffo A, Di Lauro G, Illiano E, et al. (2013) Treating Idiopathic Male Infertility with a Combination of Tamoxifen Citrate and a Natural Compost with Antioxidant and Androgen-Mimetic Action. J Steroids Hormon Sci S5: 002. doi:10.4172/2157-7536.S5-002

\section{Conclusion}

In conclusion, in this study we investigated that the association of an antiestrogen and a natural compound containing antioxidant and androgen-mimetic substances is a valid, safe and effective therapy for treating men with idiophatic oligoasthenozoospermia.

In fact we have demonstrated that the use of this combination significantly improves the number and the motility of sperms. Furthermore there is an improvement of the pregnancy rate comparing with the group taking just tamoxifen citrate and to placebo recipients.

This treatment protocol is inexpensive, safe, and easy to administer.

\section{References}

1. Sharlip ID, Jarow JP, Belker AM, Lipshultz LI, Sigman M, et al. (2002) Best practice policies for male infertility. Fertil Steril 77: 873-882.

2. Siddiq FM, Sigman M (2002) A new look at the medical management of infertility. Urol Clin North Am 29: 949-963.

3. Sigman M, Jarow JP (2002) Male infertility. In: Walsh PC, Retik AB, Vaughan ED, Jr, Wein AJ (eds.)., Campbell's Urology. (8thedn), WB Saunders Co, Philadelphia.

4. Vandekerckhove P, Lilford R, Vail A, Hughes E (2007) Androgens versus placebo or no treatment for idiopathic oligo/asthenospermia. Cochrane Database Syst Rev.

5. Sharma RK, Agarwal A (1996) Role of reactive oxygen species in male infertility. Urology 48: 835-850.

6. Martinez P, Proverbio F, Camejo MI (2007) Sperm lipid peroxidation and proinflammatory cytokines. Asian J Androl 9: 102-107.

7. Hukkanen M, Hughes FJ, Buttery LD, Gross SS, Evans TJ, et al. (1995) Cytokine-stimulated expression of inducible nitric oxide synthase by mouse, rat and human osteoblast-like cells and its functional role in osteoblast metabolic activity. Endocrinology 136: 5445-5453.

8. Nandipati KC, Pasqualotto FF, Thomas AJ, Agarwal A (2005) Relationship of interleukin- 6 with semen characteristics and oxidative stress in vasectomy reversal patients. Andrologia 37: 131-134.

9. Camejo MI, Segnini A, Proverbio F (2001) Interleukin-6 (IL-6) in seminal plasma of infertile men, and lipid peroxidation of their sperm. Arch Androl 47: 97-101.

10. Rajasekaran M, Hellstrom WJ, Naz RK, Sikka SC (1995) Oxidative stress and interleukins in seminal plasma during leukocytospermia. Fertil Steril 64: 166171.

11. Sheweita SA, Tilmisany AM, Al-Sawaf $H(2005)$ Mechanisms of male infertility: role of antioxidants. Curr Drug Metab 6: 495-501.

12. Sikka SC, Rajasekaran M, Hellstrom WJ (1995) Role of oxidative stress and antioxidants in male infertility. J Androl 16: 464- 468.

13. Wang C, Chan CW, Wong KK, Yeung KK (1983) Comparison of the effectiveness of placebo, clomiphene citrate, mesterolone, pentoxifylline, and testosterone rebound therapy for the treatment of idiopathic oligospermia. Fertil Steril 40: 358-365

14. Smals AG, Pieters GF, Drayer JI, Boers GH, Benraad TJ, et al. (1980) Tamoxifen suppresses gonadotropin-induced 17 alpha-hydroxyprogesterone accumulation in normal men. J Clin Endocrinol Metab 51: 1026-1029.

15. Brandell RA, Goldstein M (1999) Varicocele and its role in male infertility Infert Reprod Med Clin North Am 10: 471-481.

16. World Health Organization (2001) Laboratory manual of the WHO for the examination of human semen and sperm-cervical mucus interaction. Ann Ist Super Sanita 37: 1-123.

17. Comhaire FH, El Garem Y, Mahmoud A, Eertmans F, Schoonjans F (2005) Combined conventional/antioxidant "Astaxanthin" treatment for male infertility: a double blind, randomized trial. Asian J Androl 7: 257-262.

18. Adamopolous DA, Pappa A, Billa E, Koukkou E, Nicopoulou S, et al. (2003) Effectiveness of combined tamoxifen citrate and testosterone undecanoate treatment in men with idiopathic oligozoospermia. Fertil Steril 80: 914-920.
19. Ghanem H, Shamloul R (2009) An evidence based perspective to the medical treatment of male infertility: a short review. Urol Int 82:125-129.

20. Ghanem H, Shaeer O, El-Segini A (2010) Combination clomiphene citrate and antioxidant therapy for idiopathic male infertility: a randomized controlled trial. Fertil Steril 93: 2232-2235.

21. Taniguchi K, Kurata K, Suzuki M (1992) Feeding-Deterrent Activity of Some Laminariaceoum Brown Algae Against The Ezo-Abalone. Nippon Suisan Gakkaishi 58: 577-581.

22. (1996) Antioxidant Activity Of Phlorotannins Isolated From The Brown Alga Eisenia Bicyclis. Fisheries Sci 62: 923-926.

23. Okada Y, Ishimaru A, Suzuki R, Okuyama T (2004) A New Phloroglucinol Derivative From The Brown Alga Eisenia Bicyclis: Potential For The Effective Treatment Of Diabetic Complications. J Nat Prod 67: 103-105.

24. Li Y, Qian ZJ, Ryu B, Lee SH, Kim MM, et al. (2009) Chemical Components and Its Antioxidant Properties In Vitro: An edible marine brown alga, Ecklonia Cava. Bioorg Med Chem 17: 1963-1973.

25. Zhou JF, Wang XY, Shangguan XJ, Gao ZM, Zhang SM, et al. (2005) Increased oxidative stress in women with pregnancy-induced hypertension. Biomed Environ Sci 18: 419-426.

26. Potts Jm, Pasqualotto FF (2003) Seminal Oxidative Stress In Patients With Chronic Prostatitis. Andrologia 35: 304-308.

27. Tabatabaie T, Vasquez-Weldon A, Moore DR, Kotake $Y(2003)$ Free radicals and the pathogenesis of type 1 diabetes: beta-cell cytokine-mediated free radical generation via cyclooxygenase-2. Diabetes 52: 1994-1999.

28. Fubini B, Hubbard A (2003) Reactive oxygen species (ROS) and reactive nitrogen species (RNS) generation by silica in inflammation and fibrosis. Free Radic Biol Med 34: 1507-1516.

29. Jordan J, Galindo MF, Gonzalez-Garcia C, Cena V (2003) Role and regulation of p53 in depolarization-induced neuronal death. Neuroscience 122: 707-715.

30. Hsiao G, Teng CM, Sheu JR, Cheng YW, Lam KK, et al. (2001) Cinnamophilin as a novel antiperoxidative cytoprotectant and free radical scavenger. Biochim Biophys Acta 1525: 77-88.

31. Meneshian A, Bulkley GB (2002) The physiology of endothelial xanthine oxidase: from urate catabolism to reperfusion injury to inflammatory signal transduction. Microcirculation 9: 161-175.

32. Droge W (2002) Free radicals in the physiological control of cell function Physiol Rev 82: 47-95.

33. Nelson WG De Marzo AM, Deweese TL, Lin X, Brooks JD, et al. (2001) Preneoplastic prostate lesions: an opportunity for prostate cancer prevention. Ann N Y Acad Sci 952: 135-144.

34. Cui $\mathrm{H}$, Kong $\mathrm{Y}$, Zhang $\mathrm{H}$ (2012) Oxidative stress, mitochondrial dysfunction and aging. J Signal Transduct 2012:1-13.

35. Kim AR, Lee MS, Shin TS, Hua H, Jang BC, et al. (2011) Phlorofucofuroeckol A inhibits the LPS-stimulated iNOS and COX-2 expressions in macrophages via inhibition of NF-KB, Akt, and p38 MAPK. Toxicol In Vitro 25: 1789-1795.

36. Jung WK, Heo SJ, Jeon YJ, Lee CM, Park YM, et al. (2009) Inhibitory effects and molecular mechanism of dieckol isolated from marine brown alga on COX2 and iNOS in microglial cells. J Agric Food Chem 57: 4439-4446.

37. Jung WK, Ahn YW, Lee SH, Choi YH, Kim SK, et al. (2009) Ecklonia cava ethanolic extract inhibit lipopolysaccharide-induced cycloxygenase-2 and inducible nitric oxide synthase expression in BV2 microglia via the MAP kinase and NF-kappaB pathways. Food Chem Toxicol 47: 410-417.

38. Adimoelja A, Adaikan PG (1997) Protodioscin from herbal plant Tribulus terrestris $L$ improves male sexual functions probably via DHEA. Int J Impotence Research 9: 1-3.

39. Gauthaman K, Ganesan AP (2008) The hormonal effect of Tribulus terrestris and its role in the management of male erectile dysfunction: an evaluation using primates, rabbit and rat. Phytomedicine 15: 44-54.

40. Gauthman K, Adaikan PG, Prasad RN (2002) Aphrodisiac Properties O Tribulus Terrestris Extract (Protodioscin) in Normal and castrated rats. Life Sc 71: $1385-1396$

41. Adaikan PG, Gauthaman K, Prasad RN, Ng SC (2000) Proerectile pharmacological effects of Tribulus terrestris extract on the rabbit corpus cavernosum. Ann Acad Med Singapore 29: 22-26. 
Citation: lacono F, Prezioso D , Ruffo A, Di Lauro G, Illiano E, et al. (2013) Treating Idiopathic Male Infertility with a Combination of Tamoxifen Citrate and a Natural Compost with Antioxidant and Androgen-Mimetic Action. J Steroids Hormon Sci S5: 002. doi:10.4172/2157-7536.S5-002

42. lacono F, Prezioso D, Ruffo A, Di Lauro G, Romis L, et al. (2011) Analyzing the efficacy of a new natural compound made of the alga Ecklonia bicyclis, Tribulus terrestris and $\mathrm{BIOVIS}^{\circledR}$ in order to improve male sexual function . Journal of Men's Health 8: 282-287.

43. Ignarro LJ (2000) Nitric oxide: biology and pathobiology. (2ndedn), San Diego, CA: Academic Press: 3-19.

44. Herrero MB, de Lamirande E, Gagnon C (1999) Nitric oxide regulates human sperm capacitation and protein-tyrosine phosphorylation in vitro. Biol Reprod 61: $575-581$

45. Lee NP, Cheng CY (2004) Nitric oxide/nitric oxide synthase, spermatogenesis and tight junction dynamics. Biol Reprod 70: 267-276.

46. Huang I, Jones J, Khorram O (2006) Human seminal plasma nitric oxide: correlation with sperm morphology and testosterone. Med Sci Monit 12: CR103-CR106.

47. Burnett AL, Ricker DD, Chamness SL, Maguire MP, Crone JK, et al. (1995) Localization of nitric oxide synthase in the reproductive organs of the male rat Biol Reprod 52: 1-7.
48. Zini A, O'Bryan MK, Schlegel PN (2001) Nitric oxide synthase activity in human seminal plasma. Urology 58: 85-89.

49. Lewis SE, Donnelly ET, Sterling ESL, Kennedy MS, Thompson W, et al. (1996) Nitric oxide synthase and nitrite production in human spermatozoa: evidence that endogenous nitric oxide is beneficial to sperm motility. Mol Hum Reprod 2: 873-878.

50. Meiser H, Schulz R (2003) Detection and localization of two constitutive NOS isoforms in bull spermatozoa. Anat Histol Embryol 32: 321-325.

51. Herrero MB, Gagnon C (2001) Nitric oxide: a novel mediator of sperm function. J Androl 22: 349-356.

52. Thundathil J, De Lamirande E, Gagnon C (2003) Nitric oxide regulates the phosphorylation of the threonine-glutamine-tyrosine motif in proteins of human spermatozoa during capacitation. Biol Reprod 68: 1291-1298.

53. Revelli A, Soldati G, Costamagna C, Pellerey O, Aldieri E, et al. (1999) Follicular fluid proteins stimulate nitric oxide (NO) synthesis in human sperm: a possible role for NO in acrosomal reaction. J Cell Physiol 178: 85-92.
This article was originally published in a special issue, Hormonal Therapy handled by Editors. Dr. Ratna K Vadlamudi, University of Texas San Antonio, TX, USA; Dr. Baharudin Bin Abdullah, School of Medical Sciences, Health Campus USM, Malaysia 